\title{
Holistic Resilience Index: measuring the expected country resilience to pandemic
}

\author{
Salvatore F. Pileggi ${ }^{1,2}$ (D) \\ Accepted: 7 December 2021 / Published online: 20 January 2022 \\ (C) The Author(s), under exclusive licence to Springer Nature B.V. 2021
}

\begin{abstract}
This study aims to holistically measure the expected resilience of the different countries to a global pandemic like COVID-19. The proposed indicator has been designed looking at the direct and indirect impact of the COVID-19 pandemic on our society at different levels, including health and socio-economic aspects. More concretely, the resulting index has been produced by combining 11 different indicators grouped in five categories. It is actually composed of two sub-indicators that aim to measure the expected resilience according, respectively, to the data available in a given moment and to a period of development. The former sub-indicator depends on the actual values of the underpinning indicators, while the latter takes into account only their variation in a given time. In this paper we address 22 countries among the most affected by COVID-19, looking at recent pre-pandemic data and at the development in the past 20 years. As expected, the combination of the two methods determines contrasting results but also a more comprehensive analysis framework. As part of the lesson learnt, we do expect countries to prioritise the increasing of their holistic resilience to situations of pandemic.
\end{abstract}

Keywords COVID-19 $\cdot$ Indicators $\cdot$ Data analysis $\cdot$ Resilience

\section{Introduction}

While the COVID-19 pandemic crisis is in a new critical phase characterised by the massive vaccination rollout in the most developed countries (Scudellari 2020), upon scientists warns (Murdoch 2020), WHO urges nations to prepare for future pandemics as it is unlikely that this will be the last one (https://www.who.int/news/item/01-10-2020-the-besttime-to-prevent-the-next-pandemic-is-now-countries-join-voices-for-better-emergencypreparedness.), as well as we need to rethink sustainable pathways for our planet Naidoo and Fisher (2020).

Salvatore F. Pileggi

SalvatoreFlavio.Pileggi@uts.edu.au

1 School of Information, Systems and Modelling (ISM), Faculty of Engineering and IT, University of Technology Sydney, Sydney, Australia

2 Centre on Persuasive Systems for Wise Adaptive Living (PERSWADE), Faculty of Engineering and IT, University of Technology Sydney, Sydney, Australia 
A clear picture of the impact of COVID-19 in terms of human lives is provided by the John Hopkings University trought a real-time dashboard (Dong et al. 2020). Beyond those dramatic statistics, socio-economic implications are progressively being assessed (Bashir et al. 2020), pointing out a situation of generalised distress. Apart from the well-known economic issues (Nicola et al. 2020), fear, uncertainty (Chater 2020; Altig et al. 2020) and the restrictions in place in most countries (e.g. social distancing, lock-down, travel-ban) to contain the spread of the virus (Haug et al. 2020), are contributing to an even more alarming picture characterised, among others, by increasing mental illness (Fofana et al. 2020), increasing violence against women (Roesch et al. 2020), aggressive behaviour (Mazza et al. 2020), increasing concerns about the misuse or abuse of alcohol (Clay and Parker 2020) and use of illegal drugs (Zaami et al. 2020).

In this evolving situation across the different mutations of COVID-19 (Kupferschmidt 2021), most hopes rely on vaccines (Le et al. 2020) and treatments (Felsenstein et al. 2020), as well as government (Cheng et al. 2020) and individual response play a significant role (Van Bavel et al. 2020). In this complex and mostly still undefined context, the concept of vulnerability in itself should probably be redefined (Lancet 2020). At the same time, resilience becomes a key concept, looking at individuals (Killgore et al. 2020), families (Prime et al. 2020) and the whole society (e.g. in terms of health system (Legido-Quigley et al. 2020).

In the context of this work, we consider country resilience from an holistic perspective, as we are dynamically looking at a number of criteria that are ultimately combined together to likely express the expected resilience of a given country in a situation of pandemic.

This study aims to holistically measure the expected resilience of the different countries to a global pandemic. By analysing the direct and indirect impact of the pandemic on our society at different levels, including health and socio-economic aspects, 11 different indicators grouped in five categories have been selected and an index has been produced accordingly by combining them. The holistic indicator is actually composed of two sub-indicators that aim to measure the expected resilience according, respectively, to the data available in a given moment and to a period of development. The former sub-indicator depends on the actual values of the underpinning indicators, while the latter takes into account only their variation in a given time. We have computed such indicators for 22 countries among the most affected by COVID-19, looking at recent pre-pandemic data and at the development in the past 20 years. The final indicator can be computed for any other country not included in this study upon data availability, as well as input indicators may be potentially refined. As expected, the combination of the two methods determines contrasting results but also a more comprehensive analysis framework. As part of the lesson learnt in this challenging period, we do expect countries to prioritise the increasing of their holistic resilience to situations of pandemic.

The rest of the paper is organized as follows: Sect. 2 deals with materials and methods, while results are presented in Sect. 3 and discussed in context considering also current limitations in Sect. 4. Additionally, the paper includes three annexes which report, respectively, missing data, an overview of the raw data underpinning the target indicator and a summary of the development trends in the period object of analysis. 


\section{Materials and methods}

From a methodological perspective, there are basically two key characterizing aspects underlining this work: (1) the selection of indicators and (2) the computational method to combine them into a unique index. They are object of detailed discussion in the following sub-sections.

\subsection{Categories and indicators}

Looking at the impact of the global pandemic on our lives, five different dimensions have been selected to define the global resilience to pandemic of a given country. Indeed, the generic health has been integrated with an additional category that more specifically targets the healthcare infrastructure to be properly considered in a certain demographic context (demography). The socio-economic context is represented by two separate categories (economy and society).

We are not explicitly considering a category associated with the environment at this stage. Indeed, despite the existence of several researches which aim to investigate possible relationships between COVID-19 mortality/spread and environmental factors (e.g. air pollution Fattorini and Regoli 2020) as well as between COVID-19 and climate change (Beyer et al. 2021), we consider that, at the best of our current knowledge, such a category could play a less determinant role than the previously proposed ones to measure holistic resilience in the aimed extent of this study. However, we believe that we are indirectly considering certain aspects related to the environment, for instance considering the death rate (which normally also includes deaths caused by air pollution (Jerrett 2015) as an indicator.

The indicators selected for each category are reported in Table 1 . The table also includes supporting indicators, namely those indicators which are not adopted to produce the index but are used in this work to perform computations (e.g. normalization) or to discuss the current impact of COVID-19. A wished trend (or value range) is related to each indicator. It may have two values: increasing (or positive) for indicators we would like to have a positive trend or high value associated with; decreasing (or negative) when we would like the value of the indicator decreasing or, in general, as low as possible. For instance, we would like a decreasing/negative unemployment rate and an increasing/positive expenditure in healthcare.

The health infrastructure category has been proposed as, in a situation of pandemic ,the healthcare system is definitely under serious stress and, indeed, the most immediate response and management aim to keep the curve within the capability of the healthcare infrastructure. We have chosen two different indicators for this categories, the current health expenditure as a \% of the GDP and the number of hospital beds. The former provides a clear understanding of the investment in healthcare of a given country and becomes very valuable looking at its evolution in the time. The latter is a kind of approximation to consider the capability of the hospital network in a given country.

The health category pretends to capture, at a very generic level, the health status of a given country. It's hard to figure out such a figure provided by a restricted number of indicators. We have chosen the death rate and, looking at the most immediate effects, people with mental health disorders. For this last indicator, the assumption is that a country which detects and properly deals with mental health disorder is more prepared (and, therefore, more resilient) to face a significant increasing of cases. 


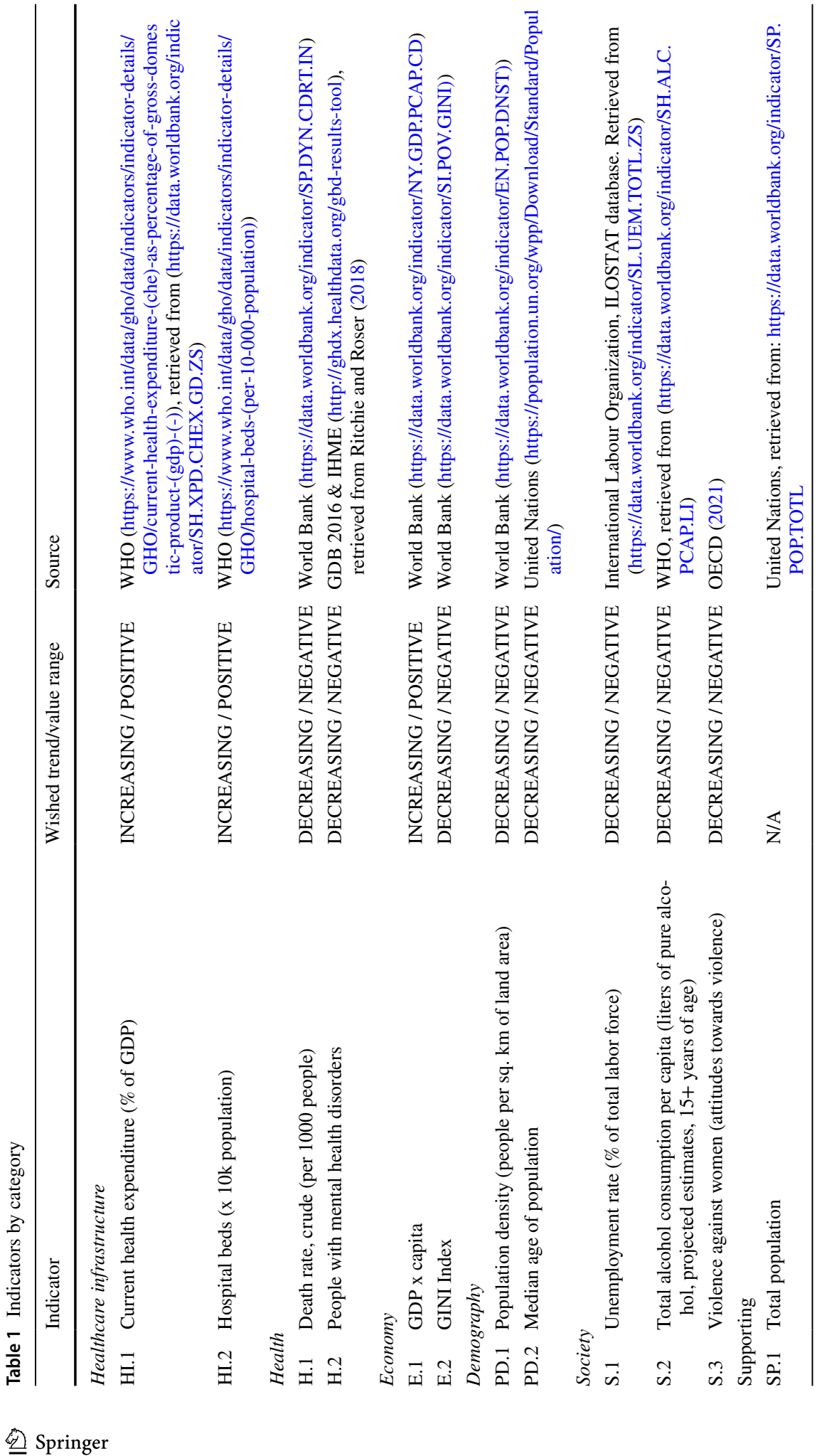




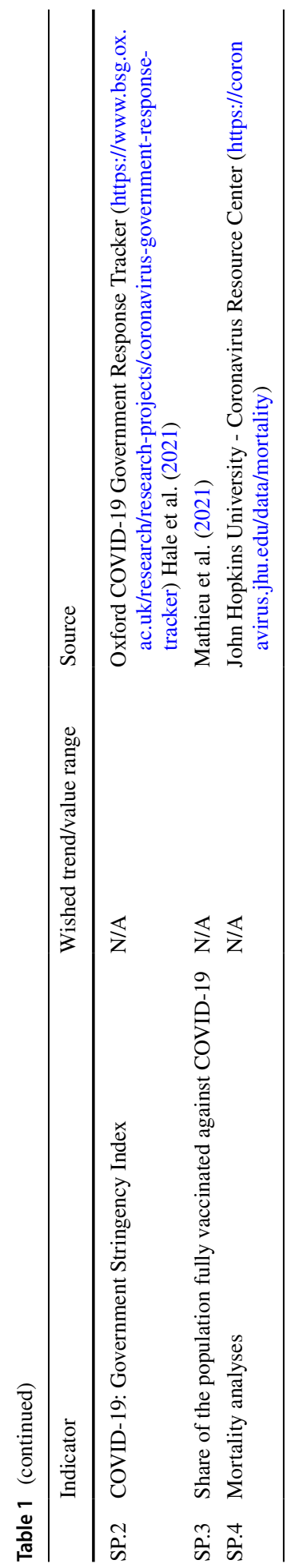


Economy plays an important role in terms of social stability and may affect governments strategy in the mid/long term. We consider the most classic economic indicator (GDP x capita) both with an indicator that measures inequality (GINI Index). In general terms, an healthy economy characterised by limited inequality is associated with higher resilience.

Demographic indicators aim to have a more in context analysis by providing key information about a given population. Looking at the characteristics of COVID-19, we have selected the population density and the median age of population. In terms of resilience, we expect low density to be a favourable factor to contrast the spreading of the virus, while a low median age may potentially contribute to a lower mortality rate.

The last category (society) is the less specific and includes three different indicators: unemployment rate, alcohol consumption x capita and attitude towards violence against women. The first indicator becomes crucial in the very likely situation of economic distress caused by a pandemic, with a largely predictable high numbers of job loss. Countries with high unemployment rates could be especially vulnerable from a socio-economic perspective. Statistics related to alcohol consumption want to reflect the potential abuse/misuse of substance (legal or illegal) under the assumption that countries with high-consumption in "normal" circumstances have less resilience as they might experiment a substantial increase in a situation of pandemic. Violence against women is representative in this case of any kind of domestic violence. The key assumption and interpretation in terms of resilience are similar to the previously discussed indicator. However, despite domestic violence is unfortunately very diffused, it is not always properly reported and statistics could be not very accurate.

As explained, the input indicators have been selected looking at current trends and studies on the impact of COVID-19 on various aspects of life. Such a dataset is considered to be pertinent and relevant within the intent and extent of this study. However, it is also expected to be refined in the future in the light of further investigation on the topic.

\subsection{Computations}

The target indicator $H R$ to measure the expected holistic resilience of a country to a situation of pandemic is composed of two different sub-indicators (Eq. 1a) as follows:

- Snapshot component $\left(H R_{c, t_{n}}^{S}\right)$ expresses the expected holistic resilience according to the data at the time $t_{n}$. As explained later on in the section, such a component is generated by computing average values and deviations from the average. Indeed, it depends on indicator values and on the set $c$ of countries considered.

- Trend component $\left(H R_{c,\left[t_{0}, t_{n}\right]}^{T}\right)$ proposes a completely different perspective, as the expected holistic resilience is computed looking at the development of raw indicators in the period of observation $\left[t_{0}, t_{n}\right]$. Since trends are modelled as variations in percentage between data at the time $t_{n}$ and at the time $t_{0}$, this sub-indicator doesn't depend on the values of the underpinning indicators but just on their variations. Additionally, the outcome associated with a given country is fully independent as it has no relationship with value associated with the other countries considered.

$$
\mathrm{HR}_{\mathrm{c},\left[\mathrm{t}_{0}, \mathrm{t}_{\mathrm{n}}\right]}=\left(\mathrm{HR}_{\mathrm{c}, \mathrm{t}_{\mathrm{n}}}^{\mathrm{S}}, \mathrm{HR}_{\mathrm{c},\left[\mathrm{t}_{0}, \mathrm{t}_{\mathrm{n}}\right]}^{\mathrm{T}}\right)
$$




$$
\begin{gathered}
\left.\mathrm{HR}_{\mathrm{c},\left[\mathrm{t}_{0}, \mathrm{t}_{\mathrm{n}}\right]}^{\mathrm{C}}=\mathrm{w}_{\mathrm{S}} \cdot \mathrm{HR}_{\mathrm{c}, \mathrm{t}_{\mathrm{n}}}^{\mathrm{S}}+\mathrm{w}_{\mathrm{T}} \cdot \mathrm{HR}_{\mathrm{c},\left[\mathrm{t}_{0}, \mathrm{t}_{\mathrm{n}}\right]}^{\mathrm{T}}\right] \\
\mathrm{w}_{\mathrm{S}}+\mathrm{w}_{\mathrm{T}}=1
\end{gathered}
$$

The two sub-indicators may be weighted and eventually combined together to produce a single indicator (Eqs. 1b and 1c).

Missing values and approximations. Missing values are reported in Annex A.1. Given the indicator $k$ for the country $c$ considered in given period of time, intuitively, a missing value at the time $i, a_{m}^{k, c}(i)$, is approximated by the closest available value $a^{k, c}(j)$, with a priority to previous values $(j<i)$ according to the time dimension. The strategy is formally described by Algorithm 1 .

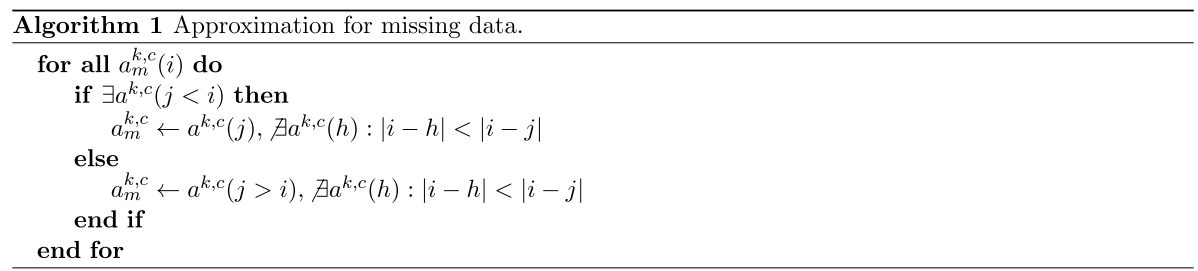

Such a simple approach is justified by the computation methods adopted which are affected primarily by extreme values along the time dimension, namely the first and the last one. If such a values are available, computations are accurate, regardless of other missing data. On the other side, if some extreme value is missed, computations are approximated. The availability of close values determine somehow the level of uncertainty.

Snapshot sub-indicator $\left(\mathrm{HR}^{\mathrm{S}}\right)$. Given a set of countries $c$ and $k$ indicators at the time $t_{n}$, the snapshot sub-indicator is computed according to Eq. $2 \mathrm{a}$ as the sum of the contributions $s_{k, c}$ of single indicators. Each indicator $k$ is associated with a weight $w_{k}$ and with a wished trend/value $\alpha_{k}$, which determines the sign of the contribution to the indicator as per previous explanations. The contribution of a single indicator (Eq. 2b) is computed as the deviation in percentage from the average value $\bar{s}_{k, c}$ of the indicator $k$ over the $c$ countries (Eq. 2c). Finally, the sub-indicator can be expressed according to a 100 scale (Eq. 2d).

$$
\begin{gathered}
\mathrm{HR}_{\mathrm{c}, \mathrm{t}_{\mathrm{n}}}^{\mathrm{S}}=\sum_{\mathrm{k}} \alpha_{\mathrm{k}} \cdot \mathrm{w}_{\mathrm{k}} \cdot \mathrm{s}_{\mathrm{k}, \mathrm{c}}\left(\mathrm{t}_{\mathrm{n}}\right) \\
\alpha_{k}=\left\{\begin{array}{l}
1 \quad \text { when } k \text { is INCREASING/POSITIVE } \\
-1 \quad \text { when } k \text { is DECREASING/NEGATIVE }
\end{array}\right. \\
\mathrm{s}_{\mathrm{k}, \mathrm{c}}\left(\mathrm{t}_{\mathrm{n}}\right)=\left(\mathrm{a}^{\mathrm{k}, \mathrm{c}}\left(\mathrm{t}_{\mathrm{n}}\right)-\overline{\mathrm{s}}_{k}\left(t_{n}\right)\right) \cdot 100 / \bar{s}_{k, c}\left(t_{n}\right) \\
\overline{\mathrm{s}}_{k, c}\left(t_{n}\right)=\left(\sum_{c} a^{k, c}\left(t_{n}\right)\right) / c \\
\operatorname{HR}_{\mathrm{c}, \mathrm{t}_{\mathrm{n}}}^{\mathrm{S} \mid 100}=\mathrm{HR}_{\mathrm{c}, \mathrm{t}_{\mathrm{n}}}^{\mathrm{S}} \cdot 100 / \max _{\mathrm{c}}\left|\mathrm{HR}_{\mathrm{c}, \mathrm{t}_{\mathrm{n}}}^{\mathrm{S}}\right|
\end{gathered}
$$


Trend sub-indicator $\left(\mathrm{HR}^{\mathrm{T}}\right)$. It is computed adopting a simplified version of the method proposed in Pileggi (2020). This sub-indicator refers to a period of observation $\left[t_{0}, t_{n}\right]$ and adopts the extreme values $t_{0}$ and $t_{n}$ for computations. The contribution $p_{k, c}$ of each raw indicator to the outcome (Eq. 3a) is defined as the variation in percentage between the two extreme values (Eq. 3b). Like the Snapshot sub-indicator, the Trend sub-indicator can be expressed in a 100 scale (Eq. 3c). This last version of the indicator depends on the values computed for other countries, while the generic version (Eq. 2a) is completely independent.

$$
\begin{aligned}
& \mathrm{HR}_{\mathrm{c},\left[\mathrm{t}_{0}, \mathrm{t}_{\mathrm{n}}\right]}^{\mathrm{T}}=\sum_{\mathrm{k}} \alpha_{\mathrm{k}} \cdot \mathrm{w}_{\mathrm{k}} \cdot \mathrm{p}_{\mathrm{k}, \mathrm{c}}\left(\mathrm{t}_{0}, \mathrm{t}_{\mathrm{n}}\right) \\
& \alpha_{k}=\left\{\begin{array}{l}
1 \quad \text { when } k \text { is INCREASING/POSITIVE } \\
-1 \text { when } k \text { is DECREASING/NEGATIVE }
\end{array}\right. \\
& \mathrm{p}_{\mathrm{k}, \mathrm{c}}\left(\mathrm{t}_{0}, \mathrm{t}_{\mathrm{n}}\right)=\left(\mathrm{a}^{\mathrm{k}, \mathrm{c}}\left(\mathrm{t}_{\mathrm{n}}\right)-\mathrm{a}^{\mathrm{k}, \mathrm{c}}\left(\mathrm{t}_{0}\right)\right) \cdot 100 / \mathrm{a}^{\mathrm{k}, \mathrm{c}}\left(\mathrm{t}_{0}\right) \\
& \operatorname{HR}_{\mathrm{c},\left[\mathrm{t}_{0}, \mathrm{t}_{\mathrm{n}}\right]}^{\mathrm{T} \mid 100}=\mathrm{HR}_{\mathrm{c},\left[\mathrm{t}_{0}, \mathrm{t}_{\mathrm{n}}\right]}^{\mathrm{T}} \cdot 100 / \max _{\mathrm{c}}\left|\mathrm{HR}_{\mathrm{c},\left[\mathrm{t}_{0}, \mathrm{t}_{\mathrm{n}}\right]}^{\mathrm{T}}\right|
\end{aligned}
$$

\section{Results}

In this section the indices previously proposed are computed for 22 different countries as a case study in the period of observation 2000-2018. Such a time-frame is considered to be suitable to address a pre-pandemic figure (Pileggi 2021). The index can be computed for any other country upon data availability. While an in-depth discussion country-by-country is out of the scope of the paper, we report an overview of computations, which also includes the contributions of the different raw indicators to the final index. Values reported assume raw indicators associated with the same weight, as well as the two sub-indicators equally contributing to the combined value.

\subsection{Snapshot sub-indicator}

The computation of the snapshot sub-indicator (Eqs. 2a and 2d ) is reported in Table 2, both with the contribution of each raw indicator. These contributions take into account of the wished trend/value $(\alpha)$ as per previous explanations.

Looking at results, roughly half of the considered countries perform under the average (negative values). Among these under-performing countries, South Africa stands out as, despite potentially favourable demographic factors, results in a very low expected resilience, from both an healthcare infrastructure and a socio-economic perspective. A very low resilience is expected also for India, which presents a much more critical demography than South Africa, but performs better in terms of social indicators. Other nine countries are associated with more moderated negative values.

On the positive side, USA and Australia out-stand, as well as Canada, Japan and Sweden. As reported in the table, other six countries are expected to be averagely resilient. 


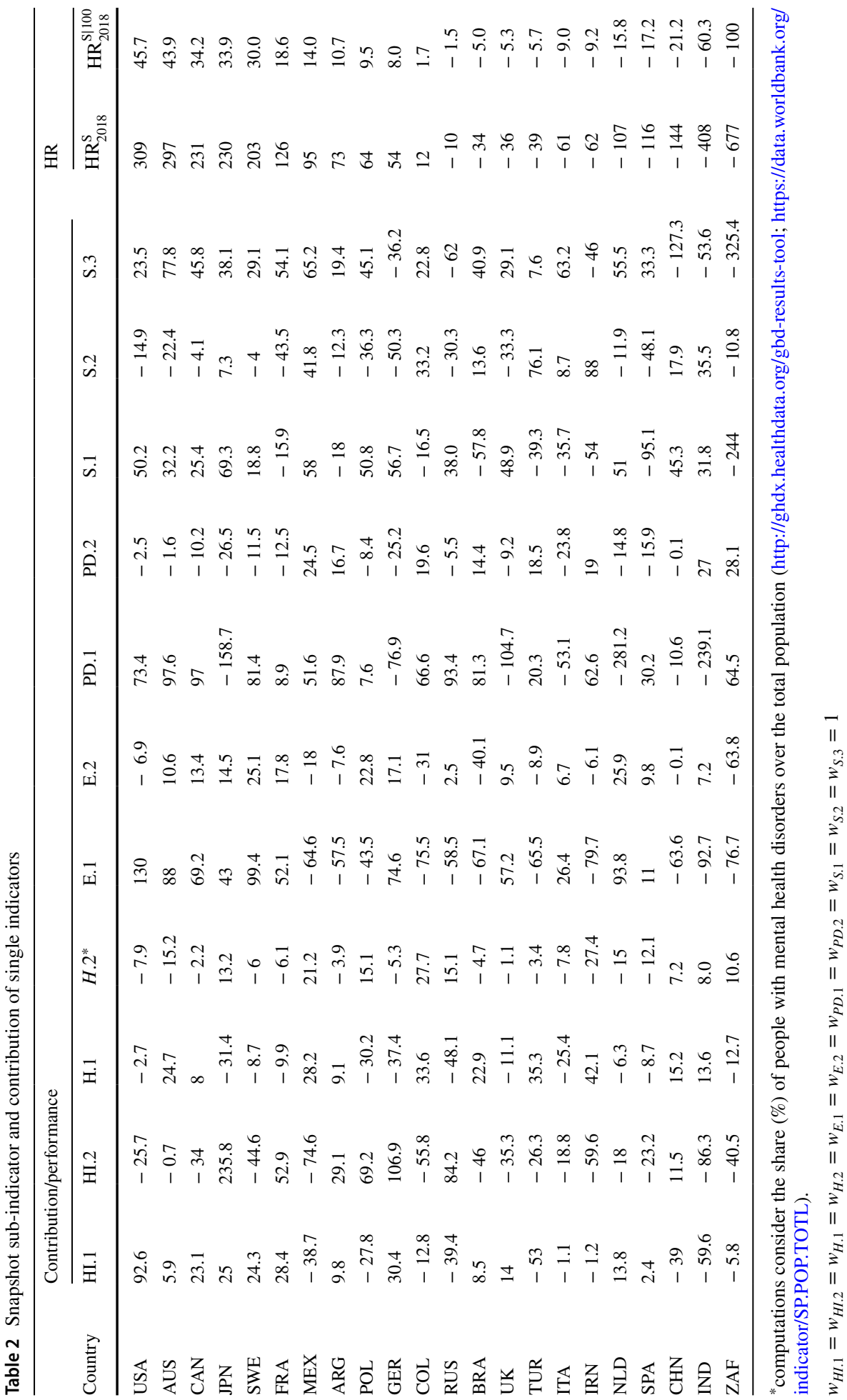




\subsection{Trend sub-indicator}

The trend sub-indicator (Eqs. 3a and 3c) is reported in Table 3, both with the contribution of each raw indicator. As for the sub-indicator previously reported, these contributions take into account of the wished trend/value $(\alpha)$.

As expected, results show a completely different picture in which most countries have increased their expected resilience, with only 3 countries (Iran, Argentina and South Africa) proposing negative values. China is the top-ranked since it has increased its expected resilience in the period of observation, sustained mostly by a strong economic growth slightly contrasted by demographic factors. Also Russia and Poland have significantly increased their expected resilience, while other 16 countries proposed a more moderated yet positive trend.

\subsection{Combined index}

The combined index (Eq. 1b) is depicted in Fig. 1, both with the values of the composing sub-indicators. As shown, seven countries propose negative values.

According to the combined index, China is the best performer by combining an impressive development in the period of observation and values of indicators still below the average in absolute terms. Also the second country in the ranking (Russia) presents a similar contrasting pattern. While Australia and USA are characterised by a solid present, resulting from a constant development, Poland has strongly increased its expected resilience in the last period. Considerations similar to Australia and USA apply to Japan, Sweden, Canada and France.

Among under-performing countries, South Africa presents a strongly negative value with a negative trend in the period of observation. India's performance is characterised by a contrasting pattern, while Iran and Argentina present a concerning trend.

\section{Discussion}

Despite its relative objectivity, the expected holistic resilience as proposed in this paper may be understood in different ways depending on the context of application. This section aims to discuss the indicator in relationship to COVID-19 response and impact. Indeed, more and more indicators are showing up to analyse and better understand effectiveness of response and actual impact.

\subsection{Expected resilience and response}

While the response to COVID-19 at the different levels is object of an intense debate within the different countries, the assessment of possible strategies as a result of the experience matured until the moment is considered a priority.

Certain approaches, such as indipendent evaluation (García-Basteiro et al. 2020), could lead to the establishment of shared principles and practice for response which is expected probably to happen in a context of increased collaboration among countries.

For instance, the Stringency Government Index (average value on available data) ( Hale et al. 2020) and the share of population fully vaccinated (Mathieu et al. 2021) are reported in Fig. 2. The former is a combined measure of the main restrictions (e.g. closures and 


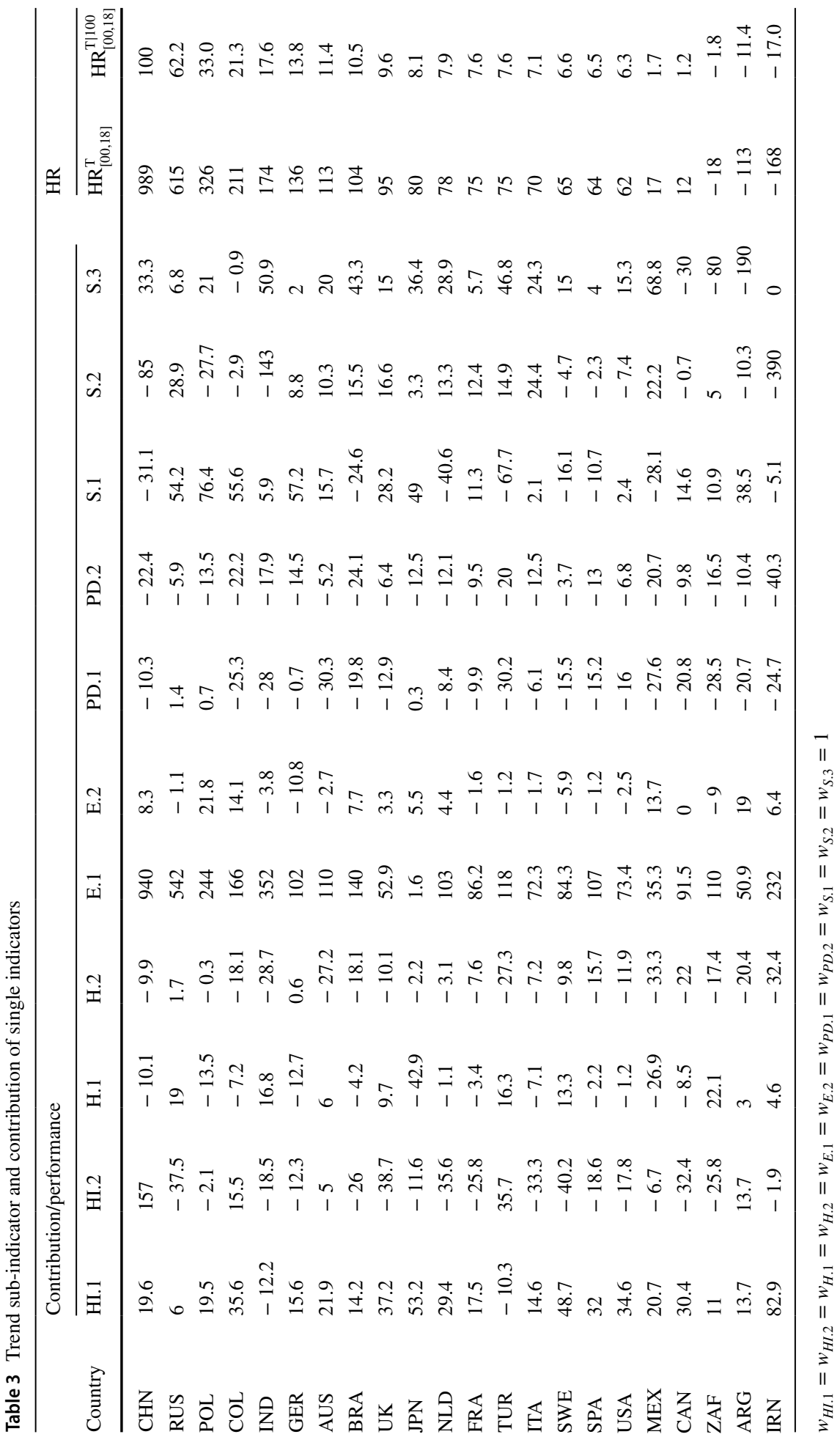




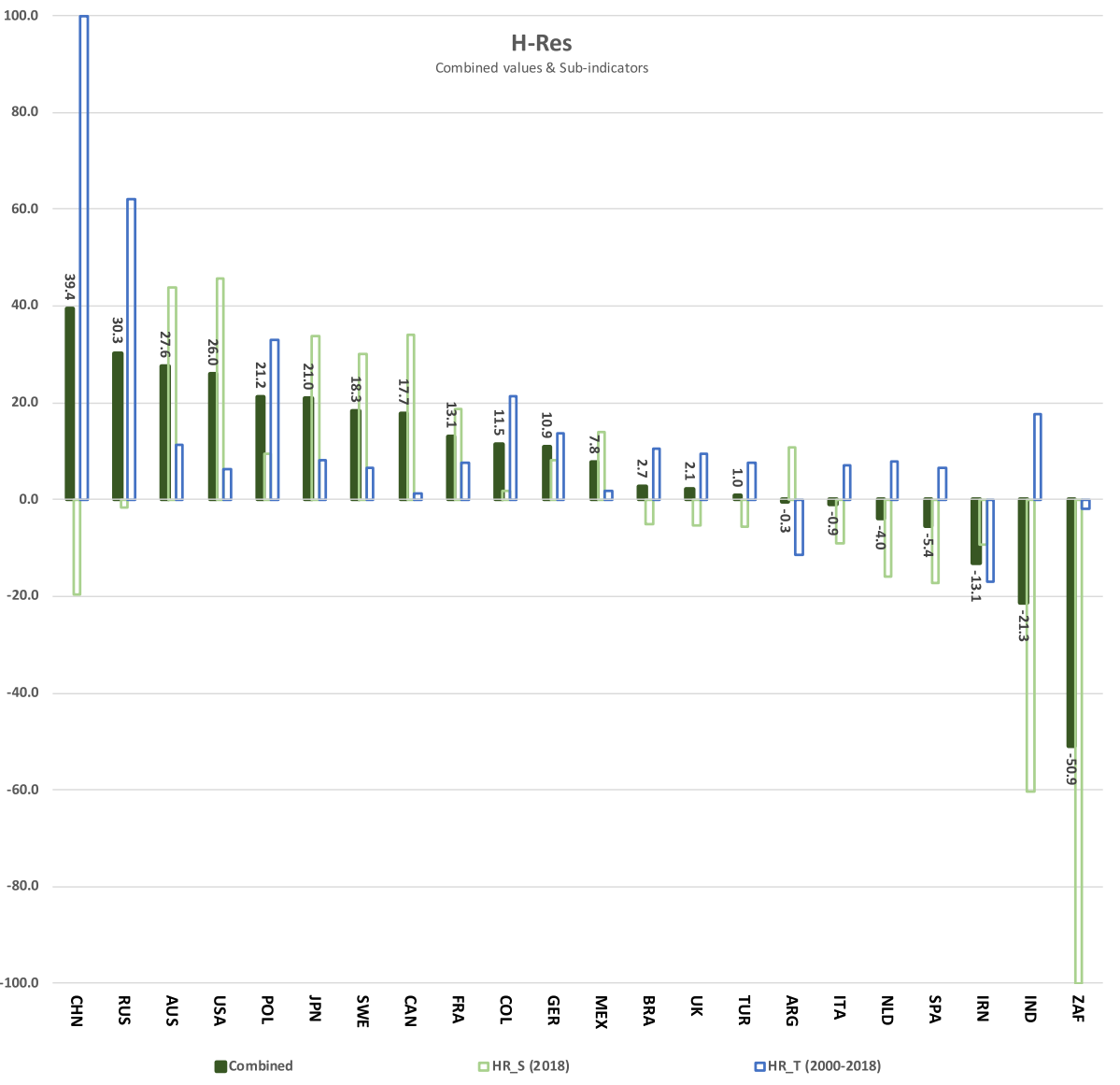

Fig. 1 Combined values and sub-indicators

travel bans) imposed by Governments in response to COVID-19, while the latter expresses the total number of people who received all doses prescribed by the vaccination protocol, divided by the total population of the country.

Based on their experience and current development, we do expect countries to be able to assess their expected resilience and increasing it by identify and mitigating major vulnerabilities. Assuming more and more reliable data and assessment models available in the next future, we will aim at better understanding the relationship between expected resilience and response.

\subsection{Expected Resilience and Impact}

According to a merely theoretical and probably naive analysis, the impact of COVID-19 should result somehow inversely proportional to the expected resilience. On one side, preparedness may have played a key role in certain situations and will become even more critical in future (WHO 2020). On the other side, the actual impact on the different countries has been determined by many factors, which are in most cases hard, if not impossible, to predict (e.g. virus mutations Starr et al. 2021; Korber et al. 2020). 


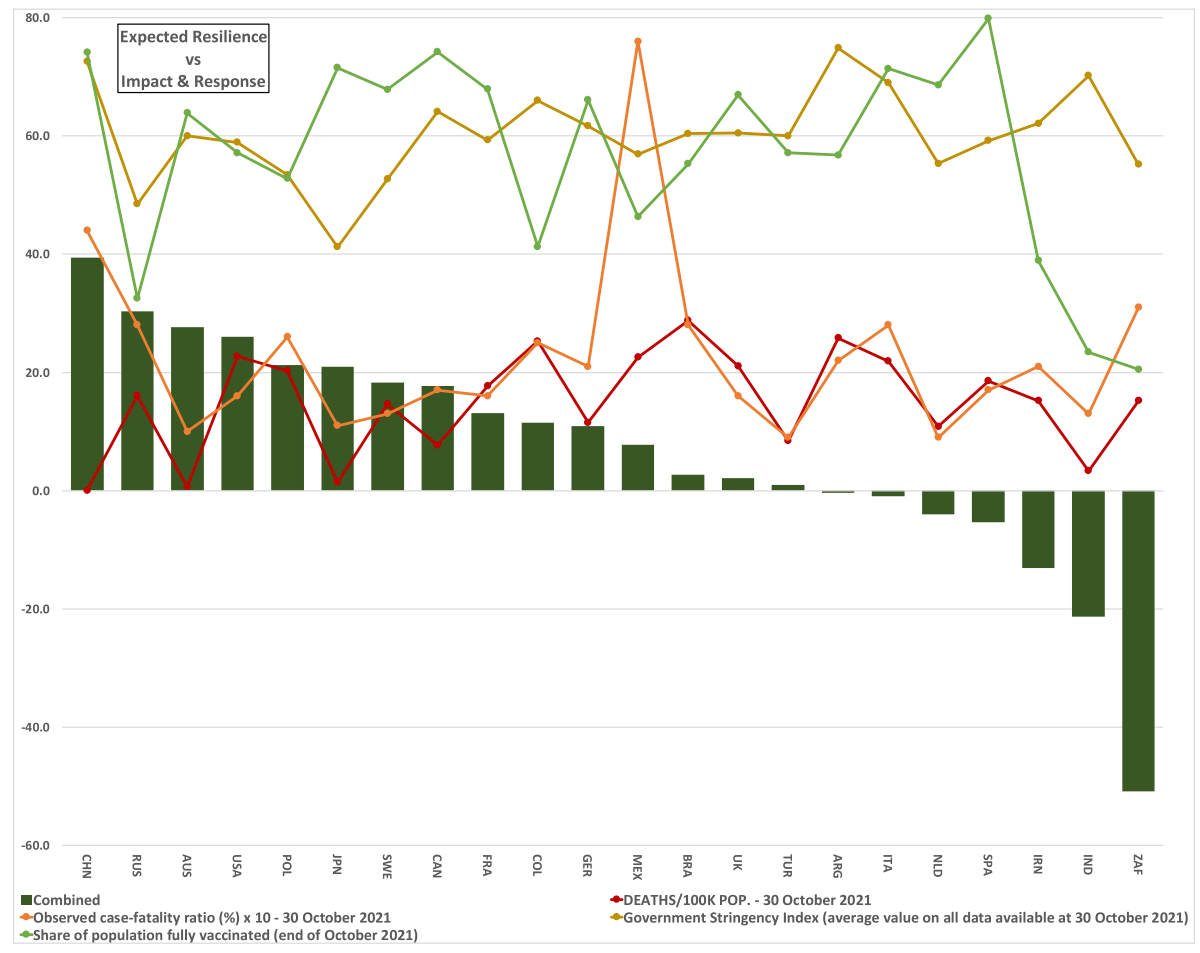

Fig. 2 Expected resilience and indicators that measure impact and response

Waiting for a post-pandemic comprehensive assessment, we report in Fig. 2 the mortality analysis provided by the John Hopkins University (https://coronavirus.jhu.edu/data/ mortality). It currently includes two different main indicators (deaths/100k people and observed case-fatality ratio).

Unpredictable factors will still probably play a role also in the future. An increasing theoretical resilience may be a simple and effective way to partially deal with uncertainty and we believe that the approach proposed in this paper can contribute to holistically measure it.

\section{Conclusions and future work}

In this paper we introduced the concept of expected resilience to a pandemic. It is the theoretical resilience expected for a country given a period of observation. Expected resilience has been approached holistically as it considers simultaneously and combines multiple perspective, including health and healthcare infrastructure, and socio-economic factors in the context of demographic aspects. The target indicator is composed of two sub-indicators which provide, respectively, a snap-shot based on the most recent values and a trend perspective based on the variations over the period of observation.

The index has been computed for 22 countries looking at data in the period 2000-2018. Results reflect overall the well-known differences and contradictions currently existing 
among the different countries and provide, if needed, further reasons to reflect about global developments and challenges.

Additionally, expected resilience has been briefly discussed in the context of COVID-19 response and impact indicators to prevent possible misleading interpretations.

Assuming more and more reliable data about COVID-19 available before too long, future work will apply sophisticated methods based on Artificial Intelligence and Optimization techniques to explicit and better understand the relationship between expected resilience and response/impact.

\section{A Annexes}

\section{A.1: Missing data}

Missing data by indicator is reported in Table 4. Missing values are reported for each country. Approximations adopted for computations have been addressed in the paper (see Sect. 2.2). Additionally, missing data critical for computations (extreme values) is highlighted in bold.

Table 4 Missing data by indicator

\begin{tabular}{|c|c|}
\hline Indicator & Missing data \\
\hline GINI Index & 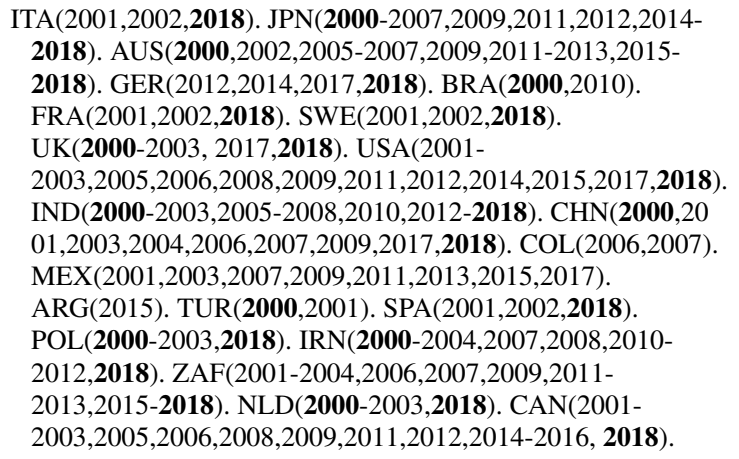 \\
\hline Hospital beds & $\begin{array}{l}\text { AUS(2016-2018). GER(2018). BRA(2018). USA(2018). } \\
\text { IND(2003,2004,2018). CNH(2018). COL(2000-2009). } \\
\text { ARG(2000-2010,2018). POL(2000-2002). IRN(2018). } \\
\text { ZAF(2000,2001,2008-2018). NLD(2014). }\end{array}$ \\
\hline People with mental health disorders & All Countries $(2017, \mathbf{2 0 1 8})$. \\
\hline Median age of population & All Countries (2001-2004,2006-2009,2011-2014,2016-2018). \\
\hline Total alcohol consumption per capita & All Countries (2001-2014,2016,2017). Canada(2000). \\
\hline Violence against women & $\begin{array}{l}\text { All Countries (2000-2013,2015-2018). Computations adopt } 2019 \\
\text { data instead of } 2018 \text { data. }\end{array}$ \\
\hline
\end{tabular}




\section{A.2: Raw data overview}

An overview of the indicators that underpin the expected holistic resilience index is provided by Figs. 3, 4, 5, 6 and 7 which represent, respectively, healthcare infrastructure, health, economical, demographic and social indicators.

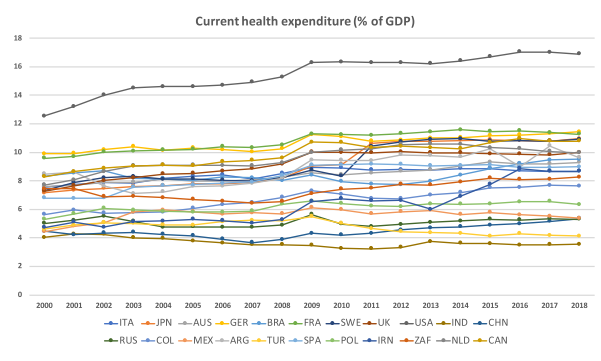

(a) Current health expenditure (\% of GDP)

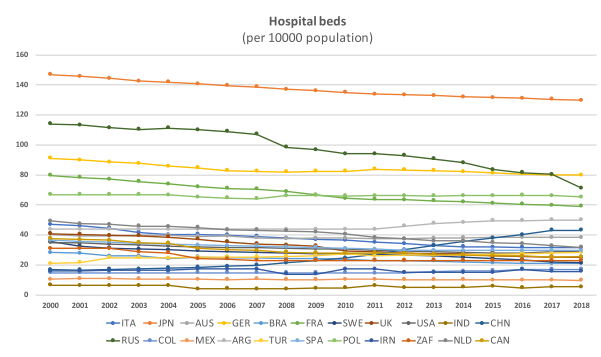

(b) Hospital beds x 10000 population.

Fig. 3 Indicators associated with healthcare infrastructure

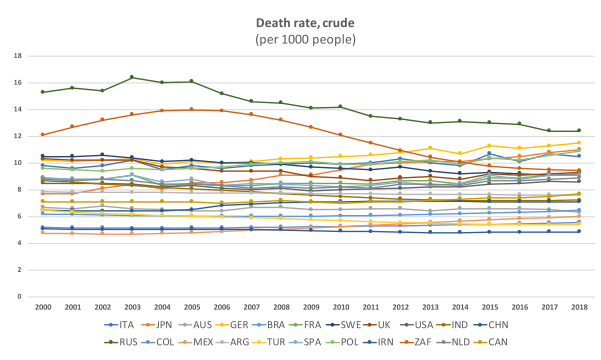

(a) Death rate $\mathrm{x} 1000$ people.

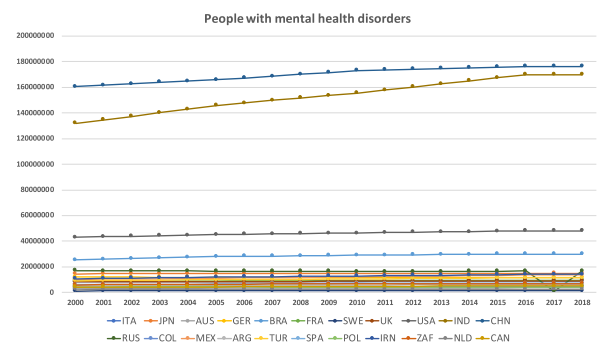

(b) People with mental health disorders.

Fig. 4 Health indicators

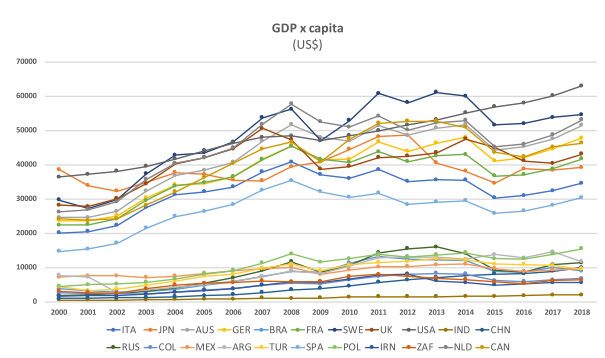

(a) GDP x capita (US\$).

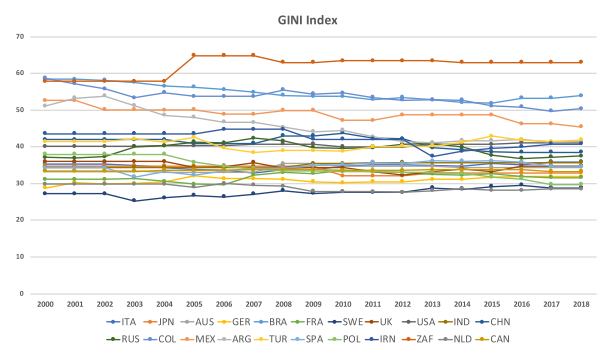

(b) GINI Index.

Fig. 5 Economical indicators 


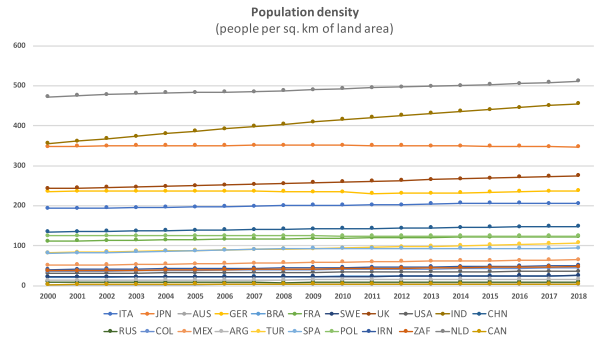

(a) Population density.

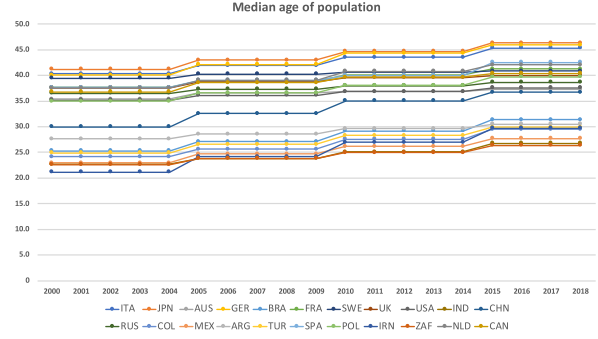

(b) Median age of population.

Fig. 6 Demographic indicators

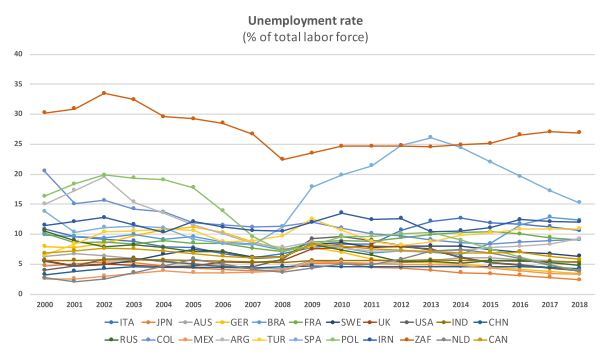

(a) Unemployment rate (\% of total labor force).

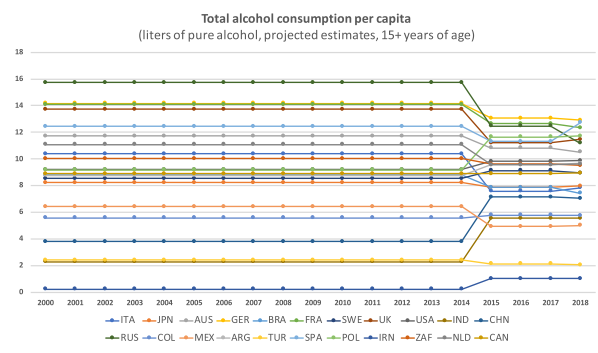

(b) Total alcohol consumption per capita.

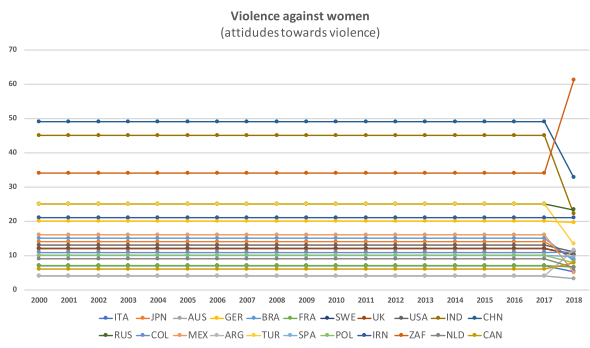

(c) Violence against women (attitudes towards violence)

Fig. 7 Social indicators

\section{Development trends by country: 2000-2018}

Development trends in the period of observation for the 22 considered countries are reported in Fig. 8. 

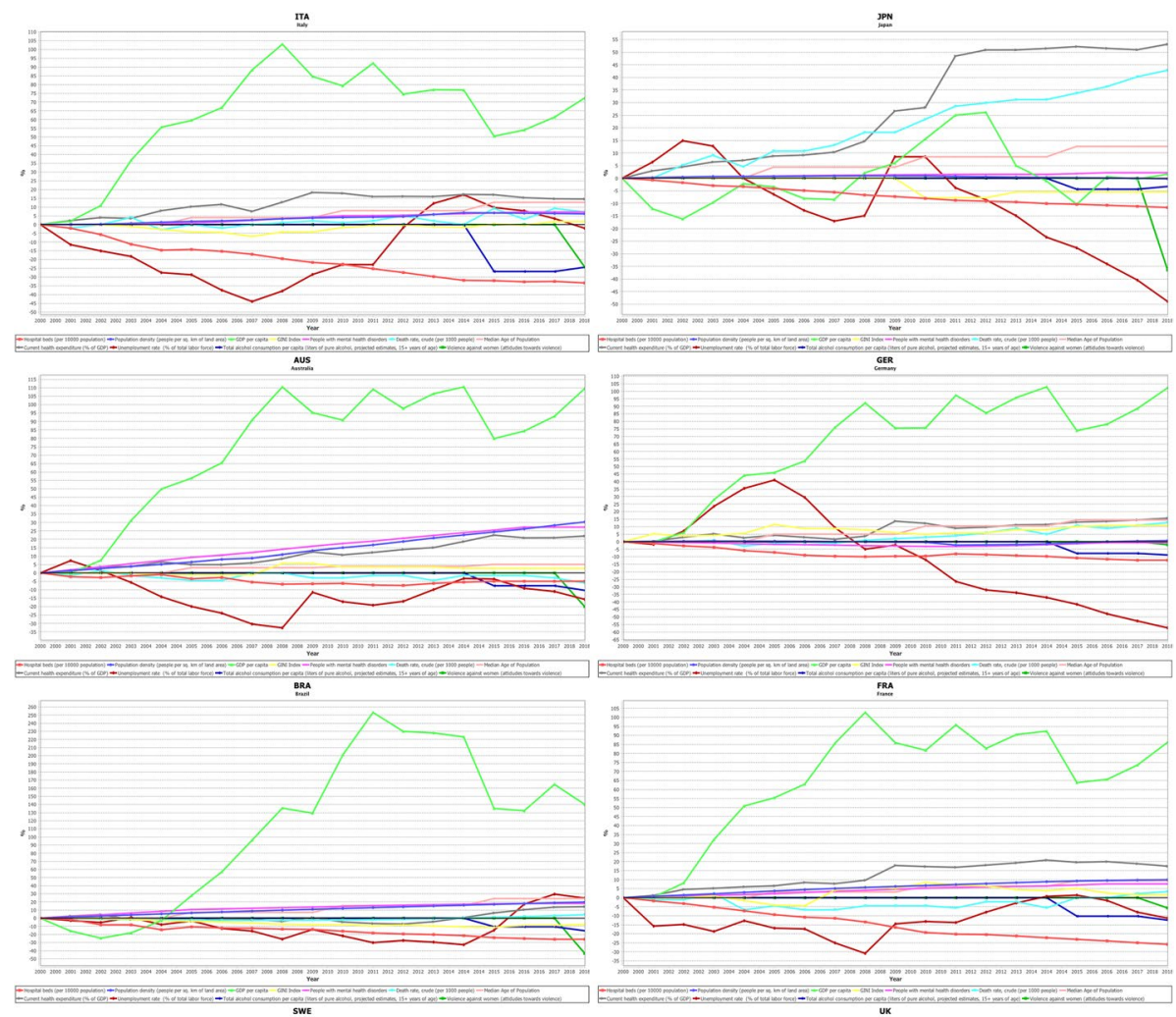

SwE
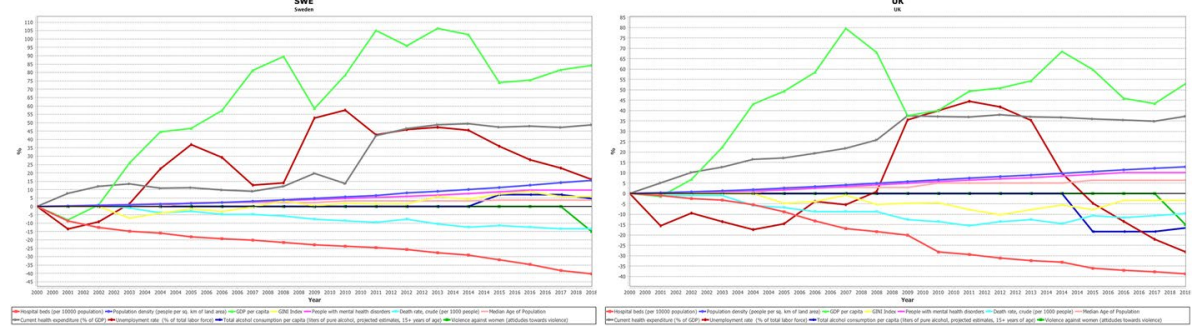

Fig. 8 Development trends in the period 2000-2018 

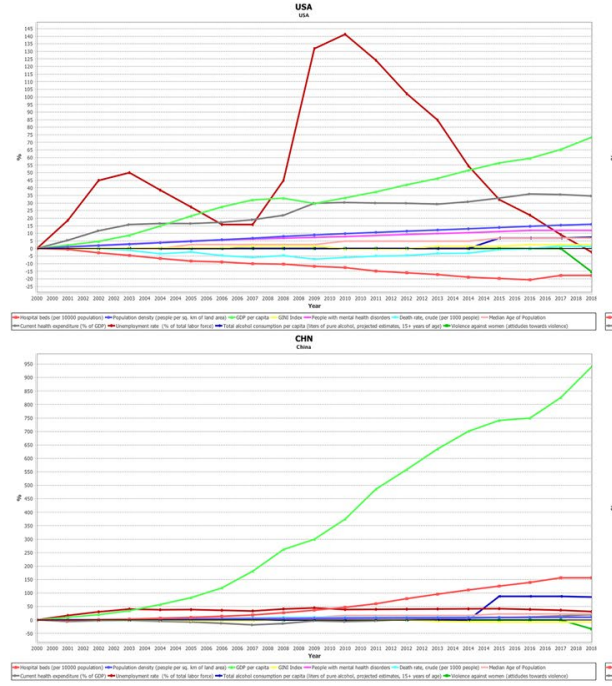

col

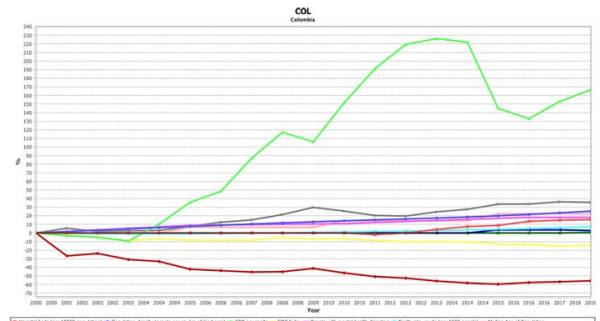

anc

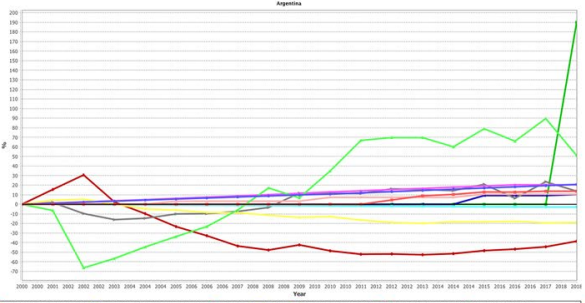

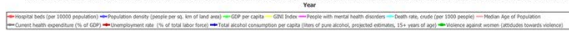

Ind

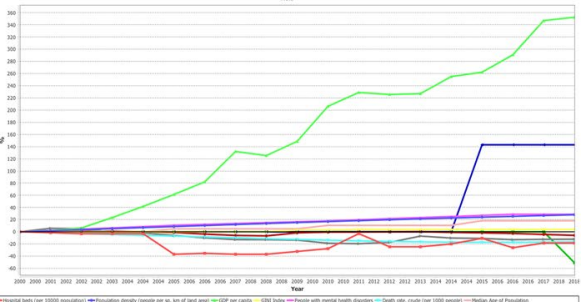

$\underset{\substack{\text { Rus } \\ \text { cuns }}}{2}$

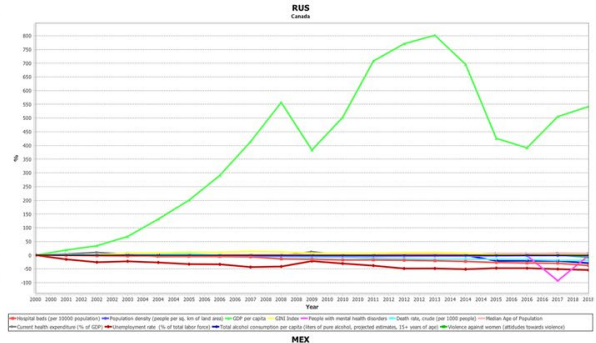

MEX

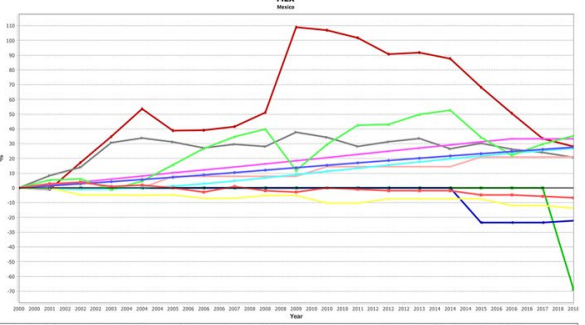

TuR

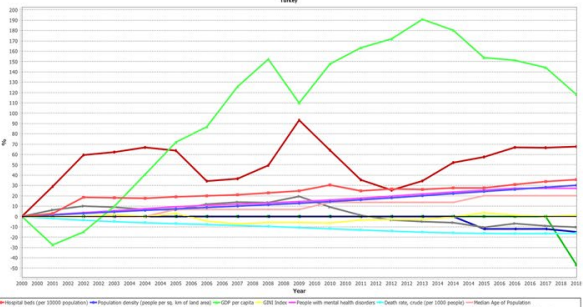

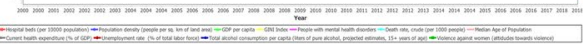

Fig. 8 (continued) 

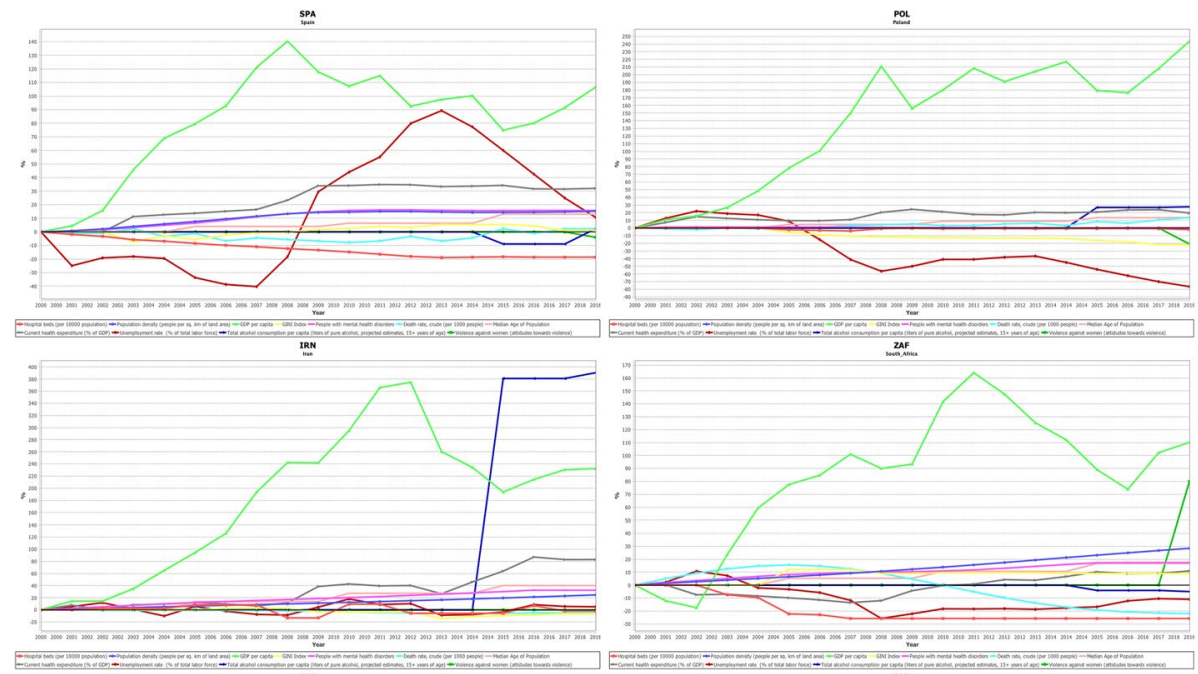

mo
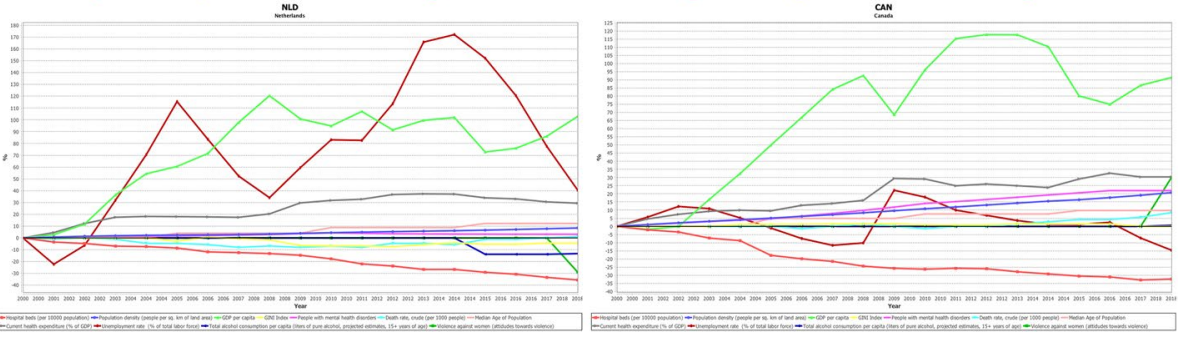

Fig. 8 (continued)

Acknowledgements I would like to thank Prof. Han Woo Park, Editor-in-Chief of the journal, for the professionalism and kindness shown throughout the review process, as well as the anonymous reviewers who provided consistent and constructive feedback.

\section{References}

Altig, D., Baker, S., Barrero, J.M., Bloom, N., Bunn, P., Chen, S., Davis, S.J., Leather, J., Meyer, B., Mihaylov, E., et al.: Economic uncertainty before and during the COVID-19 pandemic. J. Public Econ. 191, 104274 (2020)

Bashir, M.F., Benjiang, M., Shahzad, L.: A brief review of socio-economic and environmental impact of COVID-19. Air Qual. Atmos. Health 13, 1-7 (2020)

Beyer, R.M., Manica, A., Mora, C.: Shifts in global bat diversity suggest a possible role of climate change in the emergence of sars-cov-1 and sars-cov-2. Sci. Total Environ. 767, 145413 (2021)

Chater, N.: Facing up to the uncertainties of COVID-19. Nat. Hum. Behav. 4(5), 439-439 (2020)

Cheng, C., Barceló, J., Hartnett, A.S., Kubinec, R., Messerschmidt, L.: COVID-19 government response event dataset (coronanet v 10). Nat. Hum. Behav. 4(7), 756-768 (2020)

Clay, J.M., Parker, M.O.: Alcohol use and misuse during the COVID-19 pandemic: a potential public health crisis? The Lancet Public Health 5(5), e259 (2020)

Dong, E., Du, H., Gardner, L.: An interactive web-based dashboard to track COVID-19 in real time. Lancet. Infect. Dis 20(5), 533-534 (2020)

Fattorini, D., Regoli, F.: Role of the chronic air pollution levels in the COVID-19 outbreak risk in Italy. Environ. Pollut. 264, 114732 (2020) 
Felsenstein, S., Herbert, J.A., McNamara, P.S., Hedrich, C.M.: COVID-19: immunology and treatment options. Clinical Immunology 215, 108448 (2020)

Fofana, N.K., Latif, F., Sarfraz, S., Bashir, M.F., Komal, B., et al.: Fear and agony of the pandemic leading to stress and mental illness: an emerging crisis in the novel coronavirus (COVID-19) outbreak. Psychiatry Res. 291, 113230 (2020)

García-Basteiro, A., Alvarez-Dardet, C., Arenas, A., Bengoa, R., Borrell, C., Del Val, M., Franco, M., Gea-Sánchez, M., Otero, J.J.G., Valcárcel, B.G.L., et al.: The need for an independent evaluation of the COVID-19 response in Spain. The Lancet 396(10250), 529-530 (2020)

Global Burden of Disease Collaborative Network: Global Burden of Disease Study 2016 (GBD 2016) Results. Institute for Health Metrics and Evaluation (IHME), Seattle, United States (2017). http://ghdx. healthdata.org/gbd-results-tool. Accessed: 4 Jan 2021

Hale, T., Angrist, N., Goldszmidt, R., Kira, B., Petherick, A., Phillips, T., Webster, S., Cameron-Blake, E., Hallas, L., Majumdar, S., et al.: A global panel database of pandemic policies (oxford COVID-19 government response tracker). Nat. Hum. Behav. 5(4), 529-538 (2021)

Hale, T., Angrist, N. Cameron-Blake, E. Hallas, L., Kira, B., Majumdar, S., Petherick, A., Phillips, T., Tatlow, H., Webster, S.: Oxford COVID-19 Government Response Tracker, Blavatnik School of Government (2020) https://www.bsg.ox.ac.uk/research/research-projects/coronavirus-government-responsetracker. Accessed: 30 Oct 2021

Haug, N., Geyrhofer, L., Londei, A., Dervic, E., Desvars-Larrive, A., Loreto, V., Pinior, B., Thurner, S., Klimek, P.: Ranking the effectiveness of worldwide COVID-19 government interventions. Nat. Hum. Behav. 4(12), 1303-1312 (2020)

International Labour Organization, ILOSTAT database. https://ilostat.ilo.org

JHU: Mortality analyses - John Hopkings University, coronavirus resource center. https://coronavirus. jhu.edu/data/mortality

Jerrett, M.: The death toll from air-pollution sources. Nature 525(7569), 330-331 (2015)

Killgore, W.D., Taylor, E.C., Cloonan, S.A., Dailey, N.S.: Psychological resilience during the COVID19 lockdown. Psychiatry Res. 291, 113216 (2020)

Korber, B., Fischer, W.M., Gnanakaran, S., Yoon, H., Theiler, J., Abfalterer, W., Hengartner, N., Giorgi, E.E., Bhattacharya, T., Foley, B., et al.: Tracking changes in sars-cov-2 spike: evidence that d614g increases infectivity of the COVID-19 virus. Cell 182(4), 812-827 (2020)

Kupferschmidt, K.: New mutations raise specter of 'immune escape. Science 371, 329-330 (2021)

Lancet, T.: Redefining vulnerability in the era of COVID-19. Lancet (London, England) 395(10230), 1089 (2020)

Le, T.T., Andreadakis, Z., Kumar, A., Roman, R.G., Tollefsen, S., Saville, M., Mayhew, S.: The COVID19 vaccine development landscape. Nat. Rev. Drug Discov. 19(5), 305-306 (2020)

Legido-Quigley, H., Mateos-García, J.T., Campos, V.R., Gea-Sánchez, M., Muntaner, C., McKee, M.: The resilience of the Spanish health system against the COVID-19 pandemic. The Lancet Public Health 5(5), e251-e252 (2020)

Mathieu, E., Ritchie, H., Ortiz-Ospina, E., Roser, M., Hasell, J., Appel, C., Giattino, C., Rodés-Guirao, L.: A global database of COVID-19 vaccinations. Nat. Hum. Behav. 5, 1-7 (2021)

Mazza, M., Marano, G., Lai, C., Janiri, L., Sani, G.: Danger in danger: interpersonal violence during COVID-19 quarantine. Psychiatry Res. 289, 113046 (2020)

Murdoch, D.: The next once-a-century pandemic is coming sooner than you think-but COVID-19 can help us get ready. The Conversation 14,(2020)

Naidoo, R., Fisher, B.: Reset sustainable development goals for a pandemic world (2020)

Nicola, M., Alsafi, Z., Sohrabi, C., Kerwan, A., Al-Jabir, A., Iosifidis, C., Agha, M., Agha, R.: The socioeconomic implications of the coronavirus and COVID-19 pandemic: a review. Int. J. Surg. 78, 185193 (2020)

OECD: Violence against women (indicator) (2021) https://doi.org/10.1787/f1eb4876-en19 Jan 2021

Pileggi, S.F.: Is the world becoming a better or a worse place? A Data-Driven Anal. Sustain. 12(1), 88 (2020)

Pileggi, S.F.: Life before COVID-19: How was the world actually performing? Qual. Quant. 55, 1871-1888 (2021)

Prime, H., Wade, M., Browne, D.T.: Risk and resilience in family well-being during the COVID-19 pandemic. Am. Psychol. (2020)

Ritchie, H., Roser, M.: Mental health. Our world in data (2018). https://ourworldindata.org/mental-health

Roesch, E., Amin, A., Gupta, J., García-Moreno, C.: Violence against women during COVID-19 pandemic restrictions (2020)

Scudellari, M.: How the pandemic might play out in 2021 and beyond. Nature, pp. 22-25 (2020) 
Starr, T.N., Greaney, A.J., Addetia, A., Hannon, W.W., Choudhary, M.C., Dingens, A.S., Li, J.Z., Bloom, J.D.: Prospective mapping of viral mutations that escape antibodies used to treat COVID-19. Science 371(6531), 850-854 (2021)

The World Bank: Current health expenditure (\% of GDP). https://data.worldbank.org/indicator/SH.XPD. CHEX.GD.ZS. Accessed: 4 Jan 2021

The World Bank: Death rate, crude (per 1000 people). https://data.worldbank.org/indicator/SP.DYN.CDRT. IN. Accessed: 4 Jan 2021

The World Bank: GDP per capita (current US $\$$ ). https://data.worldbank.org/indicator/NY.GDP.PCAP.CD. Accessed: 4 Jan 2021

The World Bank: Gini index (World Bank estimate). https://data.worldbank.org/indicator/SI.POV.GINI). Accessed 4 Jan 2021

The World Bank: Population density (people per sq. km of land area). https://data.worldbank.org/indicator/ EN.POP.DNST). Accessed: 4 Jan 2021

The World Bank: Unemployment, total (\% of total labor force). https://data.worldbank.org/indicator/SL. UEM.TOTL.ZS. 4 Jan 2021

The World Bank: Total alcohol consumption per capita (liters of pure alcohol, projected estimates, 15+ years of age). https://data.worldbank.org/indicator/SH.ALC.PCAP.LI. Accessed 4 Jan 2021

The World Bank: Total Population. https://data.worldbank.org/indicator/SP.POP.TOTL. 4 Jan 2021

United Nations, Department of Economic and Social Affairs - Population Dynamics, Median Age of Population. https://population.un.org/wpp/Download/Standard/Population/. Accessed: 4 Jan 2021

Van Bavel, J.J., Baicker, K., Boggio, P.S., Capraro, V., Cichocka, A., Cikara, M., Crockett, M.J., Crum, A.J., Douglas, K.M., Druckman, J.N., et al.: Using social and behavioural science to support COVID-19 pandemic response. Nat. Hum. Behav. 4(5), 460-471 (2020)

WHO: Critical preparedness, readiness and response actions for COVID-19: interim guidance. 22 march 2020. Tech. Rep., World Health Organization (2020)

World Health Organization: Current health expenditure (\% of GDP). https://www.who.int/data/gho/data/ indicators/indicator-details/GHO/current-health-expenditure-(che)-as-percentage-of-gross-domesticproduct-(gdp)-(-). Accessed 4 Jan 2021

World Health Organization: The best time to prevent the next pandemic is now: countries join voices for better emergency preparedness. https://www.who.int/news/item/01-10-2020-the-best-time-to-prevent-thenext-pandemic-is-now-countries-join-voices-for-better-emergency-preparedness. 15 Feb 2021

World Health Organization - Hospital beds (per 10000 population). https://www.who.int/data/gho/data/ indicators/indicator-details/GHO/hospital-beds-(per-10-000-population). Online; accessed: 4 January 2021

Zaami, S., Marinelli, E., Varì, M.R.: New trends of substance abuse during COVID-19 pandemic: an international perspective. Front. Psych. 11, 700 (2020)

Publisher's Note Springer Nature remains neutral with regard to jurisdictional claims in published maps and institutional affiliations. 